\title{
Hacia un urbanismo renovado para la recomposición de la metrópolis. Inercias y disrupciones de la nueva ecometápolis
}

\author{
Carlos Llop ${ }^{1}$ | Borja Ruiz-Apilánez ${ }^{2}$ \\ Recibido: 09-06-2021 | en su versión final: 29-06-2021
}

\begin{abstract}
Resumen
Frente a los múltiples e impostergables desafíos de los equilibrios planetarios y su efecto sobre los modelos territoriales, el artículo propone orientaciones para la gestión de las transformaciones en clave de regeneración metabólica de la metrópolis contemporánea. La transformación parte de considerar el territorio como un bien finito que implica la preservación de los espacios abiertos no antropizados y una mayor optimización del espacio urbanizado. Una gestión mutualizadora que combine las sinergias y mutualizaciones sin dualizar y confrontrar lo urbano y lo rural, sino que más bien tienda a convivir, compensar, cooperar. A partir de la reflexión y el análisis de la cuestión de la forma urbis contemporánea, el artículo propone líneas de trabajo para la ordenación territorial, la planificación urbanística, el plan y los proyectos desde una perspectiva interdisciplinar. Una contribución que pretende hacer avanzar nuestra práctica hacia un urbanismo realmente holístico e hiperdisciplinar. Un urbanismo renovado desde los nuevas directrices estratégicas, bases proyectuales y acciones concretas basadas en principios del metabolismo social para la recomposición de la metrópolis hacia una nueva ecometápolis ya en proceso. Más allá de la polis, la metápolis. Más allá de la ciudad máquina económica, la biociudad en su territorio bioregional.
\end{abstract}

Palabras clave: Planeamiento; regeneración urbana; gestión territorial; Nueva Agenda Urbana

Citación

Llop, C. y Ruiz-Apilánez, B. Hacia un urbanismo renovado para la recomposición de la metrópolis. Inercias y disrupciones de la nueva ecometápolis. ACE: Architecture, City and Environment, 16(46), 10658. DOI: $\underline{\text { http://dx.doi.org/10.5821/ace.16.46.10658 }}$

\section{Towards a Renewed Urbanism for the Recomposition of the Metropolis. Inertia and Disruptions of the New Ecometapolis}

Abstract

\begin{abstract}
Given the multiple and urgent challenges of planetary balances and their effect on territorial models, the article outlines a set of guidelines for the management of transformations in the key of metabolic regeneration of the contemporary metropolis. The transformation is based on the concept of the territory as a finite good that implies the preservation of non-anthropized open spaces and a greater optimization of the urbanized space. The approach presented aims to form a management that combines synergies and mutualizations by not dualizing and confronting urban and rural areas, but fostering their coexistence, compensation and cooperation. Based on the reflection and analysis of the question of contemporary urban form, the article proposes lines of work for land use planning, urban planning, plans and projects from an interdisciplinary perspective. A contribution that aims to advance our practice towards a truly holistic and hyperdisciplinary urbanism. A renewed urbanism that incorporates the new strategic guidelines, project bases and specific actions based on principles of social metabolism for the recomposition of the metropolis on the way to the new ecometapolis. Beyond the polis, there is the metapolis. Beyond the machine city economic, there is the biocity in its bioregional territory.
\end{abstract}

Keywords: City planning; urban regeneration; regional planning, New Urban Agenda

${ }^{1}$ Doctor Arquitecto. Departamento de Urbanismo y Ordenación del Territorio. Universidad Politécnica de Cataluña (ORCiD: 0000-0003-4574-7864, ResearcherID: AAB-1187-2019) 2 Doctor en Territorio, Infraestructuras y Medio Ambiente. Departamento de Ingeniería Civil y de la Edificación. Universidad de Castilla-La Mancha (ORCiD: 0000-0002-2857-3965, ResearcherID: K-7562-2014). Correo de contacto: cllop@coac.net 


\section{La recomposición de la metrópolis en el nuevo milenio}

Escribía Alain Bourdin (2017) en Être métropole dans un monde incertain que el término metrópoli puede parecer claro, porque es de uso común, pero de hecho se ha centrado mucho más esfuerzo en la definición del proceso social, económico, espacial —la metropolización- que en la del objeto urbano -la metrópoli-. En efecto, lo que nos interesa es conocer los fenómenos de la explosión demográfica, de los flujos económicos, de las formas de habitabilidad en la ciudad extensa y sus efectos sobre el espacio territorial. Más allá de la delimitación nos interesa la comprensión de los procesos sociales que se difunden en una territorialidad cada vez más compleja y siempre mutante.

Para los que vivimos, trabajamos profesionalmente, y las estudiamos, las metrópolis son a la vez sujeto y objeto, recurso y reto, problema y oportunidad. La revisión de las agendas metropolitanas realizada por Ciudades y Gobiernos Locales Unidos (sin fecha, n. p.) pone de manifiesto los recursos y las contradicciones de la metropolización: "Las áreas metropolitanas concentran el 41 \% de la población urbana mundial y contribuyen de forma significativa a la riqueza de los países (en torno al 60\% del PIB mundial)" (párr. 1). Es de suma importancia re entender la composición de estas "aglomeraciones que engloban varios ayuntamientos, desbordando las divisiones administrativas e integran diferentes tipos de ciudades periféricas que forman los anillos interiores y exteriores de las áreas metropolitanas. Es en estas metrópolis donde se pueden resolver muchos de los desafíos más acuciantes a los que se enfrenta el mundo actual, pero también donde se acumulan las principales contradicciones" (párr. 1,2). En efecto, los que gestionan la eficiencia de las áreas metropolitanas se dan cuenta de las insuficiencias de su configuración administrativa y cómo el desborde funcional está provocando cambios radicales en la configuración del espacio metropolitano. Geometría variable en función de los temas que analicemos: stocks, redes y flujos. Una cuestión recurrente que imprime muchas inercias al cambio pero que no puede quedar impasible frente a las disrupciones que los sistemas metropolitanos revelan.

La distribución y organización del poblamiento y los sistemas urbano-territoriales están cambiando de forma exponencial tanto en rango como en tamaño. La variedad de formas de la urbanización mundial desborda la capacidad taxonomizadora y, en aras a una simplificación sistemática, aceptamos la convención terminológica que proponen informes internacionales como UCLG (2016, pág. 27): "Those regions across the world that are still predominantly rural will transition into urban societies [...] Urban areas range from small villages to growing intermediary cities (i-cities) and megacities".

El fenómeno metropolitano que evolucionó vertiginosamente, fruto de una explosión demográfica y de concentración de las actividades, muestra ahora un uso alargado del territorio y una delimitación cada vez más deslavazada. Si la metrópolis adquirió una reconocida madurez urbana, ahora está expresando una nueva modernidad que, a partir de las ideas de Alain Bourdin y de François Ascher, podemos denominar hiperurbana. Esta nos propone un nuevo desafío: repensar qué clase de entidad supone la metrópolis para recomponer los nuevos paradigmas morfológicos, estructurales, relacionales, metabólicos que la cualifiquen para reconducir los retos que el desarrollo sostenible nos impone con urgencia. La metropolización provoca nuevas figuras y condiciona los nuevos escenarios del futuro urbano. Decir metrópolis supone aludir a una gran diversidad de situaciones sociourbanísticas que requieren ser analizadas más allá de las simplificaciones asociadas a lo periurbano - las periferias. Un ejercicio de retrospectiva para hacer prospectiva a partir de las cuestiones que desvelan los códigos de las nuevas urbanidades y los temas que van a permitir un renovado proyecto territorial absolutamente contemporáneo y sin precedentes. ¿El postmodernismo intelectual a caballo de un postfordismo económico nos está encaminando a un posturbanismo o a un urbanismo renovado con nuevas hojas de ruta para la acción?

ACE, 16 (4.6) CC BY-ND 3.0 ES | UPC Barcelona, España | Hacia un urbanismo renovado para la recomposición de la metrópolis. Inercias y disrupciones de la nueva ecometápolis. DOI: http://dx.doi.org/10.5821/ace.16.46.10658 


\section{Aproximaciones para una nueva hoja de ruta en el proyecto y gestión urbano-territorial}

Las metrópolis requieren un nuevo relato fenomenológico para comprender cómo son y para facilitar renovadas concertaciones políticas para su gobernanza y gestión. Se trata de reflexionar sobre la pertinencia de su rol como articuladoras de la vida urbana contemporánea ampliamente cualificada y eficiente al servicio de la calidad de vida. En efecto, tal y como indican las prospectivas sobre el devenir de nuestras metrópolis mundiales, en el próximo lustro comenzaremos a comprobar la implementación de un nuevo sistema urbano global y, hacia la mitad del siglo, nuevos órdenes o grandes desórdenes territoriales. No obstante, cuando abordamos territorios concretos descubrimos que la fenomenología de la transformación urbanizadora provoca un gran mosaico diverso de situaciones territoriales. Convendrá no unificar análisis y simplificar, sino más bien revelar lo nuevo o emergente sin pretensiones de universalizar los conceptos.

Reinterpretar el mundo urbano requiere un sutil análisis de las distintas situaciones. Para ello, es preciso completar la visión cuantitativa que define las metrópolis según indicadores y magnitudes demográficas y/o topológicas. Necesitamos interesarnos por su carácter en tanto que constelaciones de habitabilidad, actividad y movilidad; con metabolismos específicos, con identidades particulares; entender los patrones de producción y consumo; indagar sobre los flujos y redes que las constituyen. Requerimos nuevas hojas de ruta para implementar las propuestas que se desprenden de las agendas que la comunidad internacional - no siempre con un acuerdo unánime- ha suscrito. El 25 de septiembre de 2015, los líderes mundiales adoptaron los Objetivos de Desarrollo Sostenible (ODS) para erradicar la pobreza, proteger el planeta y asegurar la prosperidad para todos como parte de una nueva agenda de desarrollo sostenible; la Agenda 2030 para el Desarrollo Sostenible y la COP22; la Nueva Agenda Urbana (NAU), el 20 de octubre de 2016; y el Acuerdo de París sobre el Cambio Climático, el 4 de noviembre de 2016.

Nuestro propósito es reconsiderar cuestiones que consideramos clave para el desarrollo de las realidades metropolitanas, agrupadas según el siguiente decálogo: 1) Las nuevas categorías de lo urbano. La desfronterización urbano-rural hacia la ciudad mosaico territorial; 2) La alimentación de la metrópolis y el ciclo de los nutrientes, la base de la agrópolis; 3) El ciclo de la energía y las capacidades resilientes desde la gestión local para afrontar el reto de la sostenibilidad; 4) La metrópolis de los flujos de producción y consumo; 5) La necesaria reconfiguración del espacio público y el rol de la participación ciudadana; 6) Las infraestructuras ecosistémicas como instrumento de reconfiguración de la metrópolis; 7) La movilidad y sus implicaciones sanitarias, medioambientales y sociales; 8) Un nuevo planeamiento dinámico e informado; 9) De la rehabilitación y renovación a la praxis de la Regeneación urbana integral; y 10) La representación de una lectura territorial renovada. La forma como expresión de las nuevas dinámicas y procesos.

\subsection{Las nuevas categorías de lo urbano. La desfronterización urbano-rural hacia la ciudad mosaico territorial}

La ciudad que era vista ya por la civilización griega como una entidad limitada en crecimiento, se ha desbordado explosionando por todo el territorio. Si bien este fenómeno no era impactante en términos de calidad socio ambiental es ya un problema de gran magnitud eco ambiental. Por si mismos los términos para denominar la ciudad, el territorio, y sus calidades: la urbanidad, la ruralidad, no son nada sino comportan una descripción intencionada de las características morfológicas, socio ambientales y fenomenológicas. Horacio Capel (1975) nos ofrece un buen análisis de base para la sucesiva profundización sobre "La definición de lo urbano". En efecto, su trabajo plantea una panorámica relevante y precisa sobre la complejidad de los fenómenos de urbanización en el mundo contemporáneo.

ACE, 16 (4.6) CC BY-ND 3.0 ES | UPC Barcelona, España | Hacia un urbanismo renovado para la recomposición de

la metrópolis. Inercias y disrupciones de la nueva ecometápolis. DOI: http://dx.doi.org/10.5821/ace.16.46.10658 
Después de una gran atención a describir lo urbano asistimos a un renovado interés y proliferación de escritos que reflexionan sobre la relación de lo urbano y lo rural, de la urbanidad y la ruralidad, en definitiva, de la ciudad y el territorio. La característica relevante de estas nuevas formas de abordar esta relación radica en una voluntad de desfronterizar la dualidad clásica que ha precedido en el análisis territorial tradicional. Esto marcará las nuevas formas de entender el urbanismo contemporáneo.

\subsection{La alimentación de la metrópolis y el ciclo de los nutrientes, la base de la agrópolis}

La alimentación constituye un factor clave para el desarrollo de las metrópolis. Su crecimiento ha ido en detrimento del suelo productivo de nutrientes en su entorno inmediato y ha propiciado un hinterland cada vez más grande para satisfacer sus necesidades. Hoy, sin embargo, el ciclo de los sistemas alimentarios es de una extrema complejidad y un problema base para las metrópolis como propone Carolyn Steel (2008) en Hungry City. How Food Shapes Our Lives.

La comercialización y la distribución, los cambios de hábitos y de consumo, la cocina doméstica, el desperdicio alimentario y energético, el impacto ambiental, la nutrición y la salud condicionan la naturaleza de las grandes metrópolis, exigiéndoles cambios que van más allá de la mera producción de alimentos y que afectan a cuestiones como el desequilibrio territorial, las infraestructuras, la política o el medio ambiente. En este contexto, ¿qué ciudades nos esperan? ¿Puede la urbanidad convivir con la ruralidad? ¿De qué manera la alimentación es un servicio básico para la vida? La producción de los alimentos es una actividad esencial para la supervivencia de las comunidades, de las metrópolis y sobre todo compleja en las grandes aglomeraciones urbanas. ¿Es la alimentación, al mismo tiempo, un derecho, un negocio y un delito, según la forma en que se presta este servicio a nivel social?

Tres son las cuestiones primordiales que ponen en interrogación la capacidad de prestar el servicio y los sistemas alimentarios en los territorios aludidos: la capacidad eficiente de producción, la soberanía alimentaria y/o dependencia, la seguridad alimentaria. Tres son los territorios que dan respuesta a estas cuestiones: el productivo, el de del transporte y el consumativo. En este sentido, el mosaico metropolitano será agropolitano o no será.

El desarrollo agropolitano formulado por Friedmann (1979) inicia una nueva era de la simbiosis urbano rural. Un modelo agropolitano, según lo propone Izquierdo (2009, pág. 3), se basa en una ordenación de "los espacios agrarios siguiendo una gradación territorial desde los ámbitos estrictamente urbanos y periurbanos, a los rurales más o menos intensificados y, finalmente, a los del rural campesino a los que llamamos, de forma inexacta, espacios naturales y para los que asignamos todavía una 'política de protección' a todas luces insuficiente para prevenir y corregir los problemas ecológicos que propicia el abandono campesino y la atonía del desarrollo local" y "la propuesta de desarrollo regional agropolitano se fundamenta en una en una superación de los planteamientos clásicos del manejo espacial estrictamente metropolitanos, basados, por una parte, en la concentración de actividad económica en el centro y en la renuncia expresa a lo agrario como parte activa en la gestión de la periferia urbana y, por otra, en la profusión declarativa de espacios protegidos en el medio rural campesino sobre la base de unas políticas 'proteccionistas' y 'conservadoras' insuficientes, a nuestro juicio, para preservar al territorio de la quiebra por abandono.” (pág. 4). Las metrópolis tendrán su condición agropolitana a partir de una delimitación mucha más amplia de los ámbitos territoriales que la sirven. Esta cuestión será clave para entender el alcance suprametropolitano, metapolitano de la gestión de la alimentación. Todo un reto para la ordenación del territorio y la planificación urbanística.

ACE, 16 (4.6) CC BY-ND 3.0 ES | UPC Barcelona, España | Hacia un urbanismo renovado para la recomposición de la metrópolis. Inercias y disrupciones de la nueva ecometápolis. DOI: http://dx.doi.org/10.5821/ace.16.46.10658 


\subsection{El ciclo de la energía y las capacidades resilientes desde la gestión local para afrontar el reto de la sostenibilidad}

Nuestros modelos de habitabilidad tienen una gran dependencia de la energía y son una razón considerable del uso y consumo social de la energía global. De ahí que el ecosistema territorio sea la base para conseguir mayores cuotas de resiliencia. La resiliencia entendida como la capacidad de proveer de energía necesaria sin consumir innecesariamente recursos productivos de la misma y produciéndola a partir de sistemas básicamente pasivos y sostenibles en el espacio tiempo.

El Gobierno de España (2021) en el Plan de Recuperación, Transformación y Resiliencia, pretende reorientar el proyecto de reconstrucción económico y social, justamente a través de cambios estructurales en los modos de vida mediante la transición ecológica, la transformación digital, la cohesión social y territorial y la igualdad. La apuesta hacia nuevas formas de organización de la trazabilidad del ciclo de la energía es clara: "La aceleración de la transición energética justa e inclusiva se constituye como elemento principal para la recuperación económica y como base para la reconstrucción de un modelo económico más sostenible y resiliente". El Plan Nacional Integrado de Energía y Clima 2021-2030 (PNIEC) y la Estrategia de descarbonización a largo plazo 2050 (ELP) según el Ministerio para la Transición Ecológica y el Reto Demográfico (2021, presentación, párr. 3), prevén "un gran crecimiento de la generación renovable de electricidad, lo que requiere la transformación del sistema energético, centralizado y unidireccional, en un distribuido, multidireccional, inteligente y flexible, desarrollando el almacenamiento y servicios de flexibilidad, utilizando herramientas como la digitalización de las redes, el almacenamiento y la gestión de la demanda”.

Las implicaciones de este reto para un nuevo modelo urbano y territorial requieren un sistema energético resiliente y supone un cambio radical de las formas de habitabilidad. El plan prevé una serie de actuaciones e instrumentos que ciertamente deberán incidir en la configuración de los edificios, sometidos a una profunda rehabilitación energética, y en la forma y estructura de nuestras ciudades. Por lo menos así debería ser. Nótese el tipo de actuaciones e instrumentos, que incidirán en cambios urbanos, en torno a los siguientes ejes (párr. 4): "Despliegue del almacenamiento energético, tanto detrás del contador ("behind the meter") ligado a instalaciones de consumo o generación, como conectados directamente a la red, bien stand-alone, bien hibridados a plantas de generación renovable existentes; Redes inteligentes, mediante el impulso a la inversión en digitalización de las redes, y mejora de la infraestructura eléctrica para la integración de renovables; Iniciativas para el desarrollo de nuevos modelos de negocio que provean de flexibilidad al sistema energético asociados a la transición energética, como la implantación de agregadores y especialmente los agregadores independientes o modelos de negocio en torno a / en torno a la gestión de demanda en diferentes tipologías de consumidor; Impulso al desarrollo de capacidades industriales y tecnológicas en la cadena de valor del almacenamiento, incluyendo segunda vida de equipos, la gestión de la demanda o la flexibilidad en el ámbito del sector eléctrico; Inversión pública en startups o iniciativas de nueva creación dirigidas a la innovación y nuevos modelos de negocio en el ámbito energético".

Si bien las soluciones para hacer frente al cambio climático y a la crisis energética se desarrollan en planos políticos, las traducciones técnicas son decisivas. A nivel holístico, podemos encontrar posiciones claras sobre las soluciones tecnológicas, pero debemos ser críticos sobre el grado de eficiencia. En este sentido, apreciamos los análisis de Turiel (2020) para situarnos en un escenario post-petróleo. Nuestro reto es entrever cómo contribuir desde la ordenación territorial y la planificación urbanística a un renovado sistema energético.

Los cambios en la producción, el mantenimiento y el consumo (sin orden de jerarquía) serán claves en la determinación de los renovados modelos urbanos y territoriales resilientes y sostenibles. La ciudad se enfrenta al irrenunciable reto de dar respuesta eficaz, entre otras, a las demandas de

ACE, 16 (4.6) CC BY-ND 3.0 ES | UPC Barcelona, España | Hacia un urbanismo renovado para la recomposición de

la metrópolis. Inercias y disrupciones de la nueva ecometápolis. DOI: http://dx.doi.org/10.5821/ace.16.46.10658 
eficiencia energética, ¿podremos reducir los consumos sin dejar de satisfacer las necesidades?; de equidad en relación al acceso a la energía, ¿resolveremos la pobreza energética?; y de equilibrio territorial, ¿resolveremos la producción de la demanda sin alterar la calidad socioambiental de los territorios, a partir de la proximidad o seguiremos siendo cautivos del desequilibrio entre territorios productivos y territorios consumativos?

Los sistemas urbanos internalizarán la producción que no estará relegada al territorio extractivo o productivo transformando el parque edificado, pero sobre todo ubicando infraestructuras in situ. Implicaciones ineludibles para disponer de suelo, pero también de superficies productoras, de almacenamiento y de distribución. ¿Aparecerá un nuevo sistema infraestructural que mezclará infraestructura técnica convencional con sistemas digitalizados con smart grids cada vez más sofisticadas? Los retos de la transición energética comportan una transformación a todas las escalas: edificio, barrio, ciudad y territorio. Un buen ejemplo de cómo prepararse y formarse para este gran cambio copernicano lo podemos encontrar en Claus per a un nou paradigma energètic. Anàlisi de la situació $i$ tendències. Línies de treball futures de la UPC per a la transició vers un nou model energètic (UPC, 2007), un ensayo que sintetiza los retos, las vías, los instrumentos, las técnicas para promover un gran cambio de modelo. Para el profesional del territorio, la tarea está servida siendo sensibles y concretos respecto. Un cambio en los modelos energéticos que necesitan cambios en los modelos de habitabilidad: "La transición hacia un nuevo modelo energético forma parte de un necesario cambio de paradigma de nuestra relación con el medio, un cambio que ha de transformar el metabolismo de nuestra sociedad, de nuevas formas de producción y de consumo que no se basen en la sistemática destrucción del capital natural. Y esto implica un cambio de relación con el territorio, de sistemas de infraestructuras diferentes, que harán del paisaje -de la percepción social del territorio- el eje central del debate social en tanto es la síntesis de los procesos que lo configuran" (pág. 68).

\subsection{La metrópolis de los flujos de producción y consumo}

La producción y el consumo de bienes son la base del sistema capitalista triunfante y juegan un papel fundamental en la configuración de la forma urbis desde antiguo. En nuestro entorno más próximo, las zonas urbanas todavía conservan los espacios del intercambio de bienes y el comercio -las plazas de los mercados o los zocos- que, en muchas ocasiones, todavía mantienen en menor o mayor medida su función original.

De forma análoga, la organización y la transformación del territorio también han sido un reflejo de las necesidades de los distintos sectores productivos. El incremento de la ganadería en detrimento de la agricultura transformó el territorio peninsular en la Edad Media. El impacto de ambos sectores sobre el suelo y la ordenación del territorio sigue siendo importante en nuestro país, y es cada vez mayor a nivel global.

Durante los primeros quince años del siglo XXI, mientras que los incendios han consumido una media anual de 3,9 mha, la silvicultura es la principal causa de la deforestación de nuestro planeta (6 mha/año) y la agricultura itinerante es la cuarta (3,5 mha/año), aunque ganando peso, y por encima del 4,5 mha/año desde 2014 (Europa Press Data, 2016) La deforestación es el cambio de uso de suelo que acarrea mayores pérdidas de biodiversidad, mayor degradación de los ecosistemas y de la calidad del agua y el aire, y más contribuye al cambio climático.

El sector agrícola y ganadero es considerado uno de los principales responsables del calentamiento global. Según el World Resources Institute (2016), es el causante de un 12\% de las emisiones de gases de efecto invernadero (GEI), mientras que el transporte produce el 16\%. Las tres cuartas partes corresponden al transporte por carretera, íntimamente ligado al modo en que ocupamos el territorio y planificamos nuestras ciudades.

ACE, 16 (4.6) CC BY-ND 3.0 ES | UPC Barcelona, España | Hacia un urbanismo renovado para la recomposición de la metrópolis. Inercias y disrupciones de la nueva ecometápolis. DOI: http://dx.doi.org/10.5821/ace.16.46.10658 
Pero esta es la situación a nivel global. Según datos de Climate Watch (2018), en EE. UU. cada uno de estos sectores emite, respectivamente, el 6,5 y 30\% de los GEl. En España, mientras que la agricultura es responsable del 12\% de las emisiones de GEl —igual que la media mundial- el transporte es responsable del 26\%. Este porcentaje es el mismo que en 1990 y apenas ha sufrido variaciones desde entonces. con ligeras variaciones desde entonces. Considerando que, en España, el transporte del 85\% de viajeros y del 95\% de las mercancías se realiza por carretera (Observatorio de Transporte y Logística de España, 2020) podemos asumir que, por sí solo, este representa el doble de las emisiones de GEI que el sector agrícola y ganadero en su conjunto.

El enorme peso del transporte en EE. UU. -el mayor del mundo-, en el resto de los países occidentales, en general, y en España, en particular, es fruto de nuestro modo de vida y de la forma en que hemos venido ocupando el territorio, de la mano del sistema económico y de la globalización, sobre todo a partir de la segunda mitad del siglo XX.

En nuestro entorno más próximo, la transformación del territorio metapolitano ha sucedido, de forma más intensa, durante los últimos cincuenta años. Madrid, por ejemplo, triplicó su población entre 1940 y 1970. Pasó de contar con apenas un millón de habitantes a superar los tres millones. La cifra es casi igual a la que tiene hoy en día, cincuenta años después, mientras que la ocupación del suelo del municipio aumentó 100 km², solo entre 1975 y 2005, según informe de la Dirección General de Urbanismo y Estrategia Territorial de la Comunidad de Madrid (2006), que no ofrece datos más recientes. Mientras que los cambios en el modelo urbano fueron sucediéndose de la mano de los diversos planes y programas que permitieron la rápida construcción, siempre a remolque, de una periferia que debía alojar el mayor crecimiento que experimentaría la ciudad en términos absolutos y relativos, el primer (y único) intento de reconfiguración territorial a gran escala se produce mediante la aprobación del Plan de Descongestión Industrial de Madrid.

Este situaba seis polígonos en cinco municipios situados a diferentes distancias de la capital. Los dos más próximos a poco más de $50 \mathrm{~km}$, en Guadalajara. El más alejado a casi $190 \mathrm{~km}$, en Manzanares (Ciudad Real). El plan proporcionaba tanto suelo industrial para acoger al sector secundario, como residencial, para acoger a la mano de obra necesaria. Sin embargo, mientras que otras ciudades no incluidas en el plan, crecían de la mano del desarrollo madrileño, este fracasaba, de acuerdo con las diferencias entre las previsiones de desarrollo y lo realmente ejecutado (Escudero y Gómez, 2007).

Desde entonces, el desarrollo y la ocupación territorial de la metápolis madrileña siguió adelante. Durante los años sesenta y setenta, con los tipos edificatorios vinculados a la Carta de Atenas -los bloques y torres aisladas-, que se venía utilizando en los barrios de promoción pública desde los años cuarenta y cuyo uso decae a partir de los ochenta, para dar paso a las formas importadas del suburbio norteamericano - la edificación residencial unifamiliar masiva y el centro comercial, entre grandes arterias automovilísticas que ya se venían desarrollando desde la década anterior-. Estas formas se alternarán con desarrollos de mayor densidad en los que predomina la edificación residencial colectiva en manzana cerrada, con patio comunitario generalmente privado, combinada con centros comerciales algo más integrados en la trama urbana - los denominados nuevos ensanches de los ochenta y noventa, una mutación del ensanche decimonónico como reacción a la ciudad moderna de los años anteriores-. En las dos primeras décadas del siglo XXI, siguen empleándose las formas del suburbio americano en la periferia, mientras que los programas de actuación urbanística (PAU) de la capital se construyen (todavía) según la siguiente mutación del ensanche madrileño, más agigantada, y acoge a grandes artefactos corporativos.

Mientras tanto, los flujos de producción y consumo han superado la escala de la metápolis y circulan de un lado a otro del globo ajenos al territorio, pero, paradójicamente, (des)configurándolo. Las mismas fuerzas del mercado que durante el siglo XX desmantelaron el comercio de proximidad aglutinando los puntos de venta en centros y parques comerciales - hoy de dudosa su supervivencia

ACE, 16 (4.6) CC BY-ND 3.0 ES | UPC Barcelona, España | Hacia un urbanismo renovado para la recomposición de la metrópolis. Inercias y disrupciones de la nueva ecometápolis. DOI: http://dx.doi.org/10.5821/ace.16.46.10658 
en ciudades de tamaño medio como Guadalajara o Toledo- siguen ocupando nuevo suelo, incrementando el sprawl logístico (Rivera Blasco y Ruiz Sánchez, 2021) que asegura que lleguen sus productos a nuestras casa en 24 h, con portes supuestamente gratuitos.

Algunas de las consecuencias sobre el territorio y la sociedad, derivadas del nuevo cambio de los modos de producción y consumo, ya son visibles en EE. UU. Es el caso de la población nómada retratada en la película Nomadland (Zhao, 2020). Un estilo de vida nómada que, hecho realidad, poco tiene que ver en su materialización con el que anticipaba la Walking City de los miembros de Archigram (Chalk y Herron, 1964). Al margen de las utopías pasadas o de las promesas contemporáneas de la mano de la tecnología, el siglo XXI afronta la reconfiguración del territorio, según las necesidades de los habitantes (y de los flujos) locales. Las herramientas para el análisis de la situación actual (p. ej.: Laínez-Plaza et al, 2018; Ruiz y Marmolejo, 2008) son ya una realidad, aunque sigamos desarrollándolas y mejorándolas.

\subsection{La necesaria reconsideración del espacio público y el rol de la participación ciudadana}

Los periodos de confinamiento, la limitación de los movimientos y la restricción de las interacciones sociales derivados de la pandemia de covid-19 en la que nos vemos envueltos ha aumentado el interés de la ciudadanía por el espacio público urbano y le ha hecho más consciente de su actual estado — de sus limitaciones y de sus posibilidades y, también, de sus potencialidades - El espacio público ha sido objeto de debate, reflexión, investigación a lo largo del siglo XX y lo sigue siendo. Desde una perspectiva urbanística, la propuesta más radical de transformación conceptual y física del espacio público urbano vino de la mano de los Congresos Internacionales de Arquitectura Moderna, sobre todo a partir de la publicación de La Carta de Atenas (Le Corbusier, 1943) y de la internacionalización de la arquitectura moderna durante la posguerra de la Segunda Guerra Mundial. Las principales consecuencias de esta radical transformación física de los entornos urbanos y la generalización del uso del automóvil fueron el deterioro de la calidad ambiental, declive de las actividades sociales y el aumento de la inseguridad. La migración hacia la periferia suburbana característica de la segunda mitad del siglo XX significó también la migración de una gran parte de la actividad social desde el espacio público (de propiedad pública) hacia otros espacios. Fundamentalmente, de dos tipos: espacios colectivos al aire libre de propiedad privada y acceso restringido (patios de manzana comunitarios, urbanizaciones privadas, clubes deportivos...) y espacios privados (o privatizados) de aparente libre acceso (centros o parques comerciales cubiertos o al aire libre, infraestructuras de comunicación, campus universitarios...).

Desde Jane Jacobs (1961) hasta Françoise Choay (1994) muchos autores han declarado la muerte de la ciudad, de la urbanidad o de lo urbano, tratando de describir los nuevos asentamientos humanos - la ciudad difusa (Indovina, 1990), la ciudad límite (Garreau, 1991), la metápolis (Ascher, 1995), la metrópolis fragmentada (Barnett, 1996) - con la esperanza y el propósito de que su reconfiguración y revitalización es posible.

El siglo XXI tiene ante sí este desafío y el espacio público es el lugar sobre el que mayor capacidad de actuación tienen la administración y la ciudadanía (Ruiz-Apilánez et al., 2014). Borja y Muxí (2003) apuntaban al inicio del siglo que "es fundamental redefinir los espacios públicos urbanos en las áreas de nuevos crecimientos [...] hacer de los lugares de conexión lugares con sentido [...] atribuir a las áreas de nueva centralidad características de lugar central".

Sin embargo, en el caso de España, aunque algunos barrios o desarrollos de los años cincuenta a setenta están recibiendo atención y son objeto de proyectos de regeneración urbana de menor o mayor alcance, la ciudad del último siglo sigue a la espera de ser reestructurada mientras las áreas

ACE, 16 (4.6) CC BY-ND 3.0 ES | UPC Barcelona, España | Hacia un urbanismo renovado para la recomposición de la metrópolis. Inercias y disrupciones de la nueva ecometápolis. DOI: http://dx.doi.org/10.5821/ace.16.46.10658 
centrales recibiendo mayor atención. Valga como ejemplo el caso de la ciudad de Barcelona, que, desde las últimas dos décadas viene dirigiendo sus mayores esfuerzos a la reestructuración del Ensanche de Cerdá, que también es necesaria.

La diferencia entre una y otra estriba en que, mientras en la ciudad tradicional, el rediseño del espacio público pasa, sobre todo, por una redistribución del espacio disponible para cada modo de transporte, al tiempo que se intensifica su vegetación, se permeabiliza su pavimento y se mejoran las condiciones espaciales para facilitar la realización de otras actividades sociales de carácter estacionario, en la ciudad del siglo XX, el modo de abordar la reconfiguración del espacio público no es evidente. El signo de los tiempos nos dice que ha de guiarse por los principios de sostenibilidad ambiental y social —el económico se da por supuesto-.

En relación con el primero, será fundamental considerar el ciclo del agua urbano y aprovechar las posibilidades que tengamos de favorecer el enriquecimiento de la flora y fauna urbanas. En cuanto al segundo, habrá que evitar el desplazamiento de los actuales usuarios del espacio público y favorecer la multifuncionalidad, buscando mejorar la cohesión social de los ciudadanos de distintas edades y nacionalidades, favoreciendo el encuentro y la comunicación (Leal y Leyva, 2011).

Precisamente por eso, es más necesario que nunca dar voz a la ciudadanía y que esta se involucre en los procesos de transformación urbana. En este sentido, algo venimos avanzando en los últimos años, y cada vez es menos frecuente encontrarse con procesos de transformación del espacio público que no cuenten con algún proceso de participación ciudadana. En la propia ciudad de Barcelona, hay experiencias muy interesantes de participación y co-diseño del espacio público, en muchas ocasiones de la mano de estudiantes y docentes e investigadores universitarios Sève y Redondo (2020). Las intervenciones de carácter temporal también son una herramienta útil a tener en cuenta que nos puede permitir ensayar las posibles soluciones antes de implementarlas de forma más definitiva.

Sin embargo, conviene tener presente la escalera de la participación ciudadana que proponía Arnstein (2019) a finales de los sesenta. De los ocho niveles, los dos primeros - manipulación, terapia - no eran considerados participación, los tres siguientes lo eran de una forma meramente simbólica información, consulta, asesoría- y solo los tres últimos suponían una cesión real de poder a la ciudadanía - colaboración, delegación de poder y control ciudadano- En nuestro entorno, muchos de los procesos supuestamente participativos no superan el nivel de la participación simbólica.

Más allá de la calidad de su urbanización - generalmente mediocre- el espacio público de la ciudad del último medio siglo adolece, con frecuencia, de dos características que le reducen las probabilidades de ser utilizado: definición y escala humana. Una tercera, le reduce todavía más la posibilidad: es superabundante. Jacobs (1993) y Gehl (2010) han insistido en la importancia de dotar de estas características al espacio público de nuestras ciudades. Para ello, los edificios especialmente sus plantas bajas, que son las que están a la altura de las personas - juegan un papel fundamental. La necesaria compactación de la periferia residencial contemporánea (Górgolas, 2018), podemos abordarla de forma simultánea. Una aproximación en la que todavía queda mucho por explorar.

\subsection{Las infraestructuras ecosistémicas como dispositivos de reconfiguración de la metrópolis}

Las propuestas urbanísticas de finales del siglo XIX y de la primera mitad del XX trataron de dar respuesta a la desvinculación entre personas y medio natural que había supuesto la industrialización de distintas formas, que podemos organizar según tres clases. La primera, aproximando la naturaleza a los ciudadanos, creando parques de gran escala o facilitándoles el acceso a espacios de alto valor

ACE, 16 (4.6) CC BY-ND 3.0 ES | UPC Barcelona, España | Hacia un urbanismo renovado para la recomposición de la metrópolis. Inercias y disrupciones de la nueva ecometápolis. DOI: http://dx.doi.org/10.5821/ace.16.46.10658 
natural, como los parques y los bulevares arbolados de Haussmann para París. La segunda, llevando a las personas al campo, como pretendía la ciudad jardín de Howard. La tercera, creando un nuevo hábitat híbrido urbano-natural, como vemos en distintas propuestas de Le Corbusier.

La intención última de todas las propuestas puede que fuese común: proporcionar a las personas los beneficios de la naturaleza y de la ciudad. Le Corbusier nos mostraba en 1922, en el Salon d'Automne de Paris, su utopía con una perspectiva de la Ville Contemporaine, con las sillas y las mesas en primer plano y los rascacielos al fondo, alzándose hacia el cielo por encima de una avioneta, en medio de una vegetación exuberante surcada por vías de comunicación a distintos niveles. Howard (1898) nos transmitía la idea de forma eficaz con el diagrama de los tres imanes. El de la ciudad, el del campo y el que, fundiendo el campo y la ciudad, aseguraba las ventajas de ambos mundos deshaciéndose de sus inconvenientes.

Nada más lejos de la realidad. El devenir de los asentamientos humanos durante el siglo XX — guiado, en gran medida, por las dos propuestas anteriores- supuso una explosión en la ocupación del suelo a costa de la naturaleza, que quedaba anulada en la mayoría de los casos.

Ante la lamentable situación que ya se evidenciaba hace medio siglo, la única alternativa era comenzar a proyectar con la naturaleza. Las ideas de McHarg (1969) para abordar la planificación de los desarrollo urbanos siguen siendo hoy tan vigentes como, en gran medida, todavía ignorados —a pesar, incluso, de las prescriptivas evaluaciones de impacto ambiental-.

El siglo XXI debería adoptar la propuesta de McHarg, como un manual de planificación o reconfiguración de cualquier elemento del medio construido. De la planificación territorial al rediseño de una calle o una casa. Un manual para la renaturalización de la metápolis hacia una ecometápolis que supere la dicotomía naturaleza-ciudad.

Esta renaturalización de la ciudad ha de minimizar el impacto de la urbanización en el ciclo del agua, así como en los ecosistemas preexistentes o actuales. En el suelo urbano y en su entorno. Esto suponer reconfigurar los ámbitos más antropizados reconsiderando su efecto y su posible nuevo papel dentro del ciclo del agua y restaurar las preexistencias o potencialidades medioambientales, así como los principales hábitats y corredores de fauna y flora, íntimamente relacionados con la red hidrológica.

La Comisión Europea (2013b), consciente de la reinante discontinuidad entre los ámbitos naturales o menos antropizados derivada de la expansión indiscriminada del suelo urbano y de la elevada densidad de infraestructuras - sobre todo de transporte terrestre-en su territorio (Jaeger et al., 2011), adoptó en 2013 una estrategia para desarrollar una infraestructura verde comunitaria, que proporcione a la sociedad "soluciones que trabajen con [énfasis agregado] la naturaleza y no en su contra, donde esto tenga sentido desde una perspectiva económica y medioambiental” (párr. 2). La ilusión que produce la posible alusión a McHargh, evidente en estas palabras del comisario europeo de medio ambiente Potočnik, decae con la referencia monetaria del final de la frase, al tiempo que nos recuerda el origen - ¿y la razón de ser? - de la Unión Europea. Dependerá de qué se considere a la hora de evaluar las acciones desde una perspectiva económica. Si consideramos todos los factores, las consecuencias y el ciclo de vida completo de cada intervención urbano-territorial, la sostenibilidad ambiental, social y económica convergen. Pese a lo que puedan sugerir los análisis cortoplacistas, las soluciones de la mano de la naturaleza son las socialmente más justas y económicas a largo plazo.

La Comisión Europea (2013a) insiste por ello en subrayar los beneficios o el retorno económico de la inversión en infraestructura verde, que define como un "una red estratégicamente planificada de áreas naturales y seminaturales de alta calidad con otras características ambientales, que está diseñada y administrada para brindar una amplia gama de servicios ecosistémicos y proteger la biodiversidad tanto en entornos rurales como urbanos" (pág. 7).

ACE, 16 (4.6) CC BY-ND 3.0 ES | UPC Barcelona, España | Hacia un urbanismo renovado para la recomposición de la metrópolis. Inercias y disrupciones de la nueva ecometápolis. DOI: http://dx.doi.org/10.5821/ace.16.46.10658 
La política puesta en práctica en los últimos años ha expandido el concepto de infraestructura verde a infraestructura verde y azul, haciendo énfasis en la importancia de la componente hidráulica. La UE fomenta todo tipo de iniciativas a todas las escalas y de toda condición. Toda acción cuenta, por pequeña que sea, o aparente serlo. Al mismo tiempo, hay en marcha proyectos más ambiciosos como el cinturón verde europeo, que va desde el Ártico finlandés hasta el Mediterráneo griego a través de Alemania y más de una decena de países.

El desarrollo de una infraestructura ecosistémica capaz de comunicar el verde urbano (existente o a desarrollar) con los espacios naturales de su entorno (existentes, a regenerar o a desarrollar) tendrá numerosos beneficios para el medio ambiente y, en consecuencia, para las personas. Algunos evidentes, ligados a la mejora de la calidad del aire y el agua, la estabilización y enriquecimiento de los suelos, o el aumento de biomasa y biodiversidad. Otros menos evidentes, pero igualmente importantes para las personas, están ligados al bienestar físico y psicológico que nos proporciona el contacto con elementos naturales. El conjunto de estos 'servicios' de los ecosistemas deben integrarse en los procesos de valoración de propuestas y toma de decisiones.

\subsection{La movilidad y sus implicaciones sanitarias, medioambientales y sociales}

El movimiento de las personas ha ocupado un lugar central en la planificación urbana y territorial desde los inicios disciplinares del urbanismo occidental hasta nuestros días. En sus comienzos, este papel protagonista es evidente en nuestro ámbito más próximo, donde las teorías y propuestas urbanas de (Cerdá, 1859, 1867) o Arturo Soria (materializada a partir de 1894) se fundamentan, entre otras, en las necesidades del transporte metropolitano - en Barcelona, entre el Ensanche y la comarca-, o son, incluso, su razón de ser —en el caso de la Ciudad Lineal de la corona metropolitana de Madrid-. Y ambos deducen las dimensiones y secciones del viario a partir de las necesidades de transporte urbano.

A lo largo del siglo XX, la morfología urbana no puede entenderse sin la movilidad. Declarada cuarta función principal del urbanismo por la Carta de Atenas (Le Corbusier, 1943), la importancia de la circulación_circuler - no hizo sino aumentar durante el siglo pasado, constituyéndose en la principal estructuradora del territorio y de la ciudad (Dupuy, 1991). Para nosotros, es, sin duda, un vector fundamental para abordar la configuración de la metrópolis contemporánea y sus diversas mutaciones.

El nuevo siglo ha puesto el énfasis en las implicaciones sanitarias, sociales y medioambientales de la movilidad y sus infraestructuras. La relación entre el transporte de personas y 'la salud podemos decir que es oficial desde la publicación, en el cambio de siglo, de la monografía Transport, Environment and Health (Dora y Phillips, 2000), a cargo de la Oficina Regional Europea de la Organización Mundial de la Salud (OMS). Esta ya apuntaba que el impacto negativo del tráfico motorizado se produce a diversos planos: a) la contaminación acústica -un factor de estrés ambiental omnipresente y subestimado-; b) el importante impacto de la contaminación del aire; c) los efectos sobre la salud y bienestar mental, y d) los accidentes y sus consecuencias lesivas o mortales. Sin embargo, los modos blandos o activos —el peatonal y el ciclista, fundamentalmentepueden reportar notables beneficios. Por un lado, la reducción de la contaminación acústica y del aire y del número y gravedad de los accidentes y sus consecuencias. Por otro, los derivados de la práctica frecuente de ejercicio físico: reducción significativa de las probabilidades de desarrollar enfermedades coronarias, diabetes y obesidad e hipertensión; descenso de la presión arterial en hipertensos; disminución de la osteoporosis; alivio de los síntomas de depresión y ansiedad; y, entre la tercera edad, prevención de caídas.

ACE, 16 (4.6) CC BY-ND 3.0 ES | UPC Barcelona, España | Hacia un urbanismo renovado para la recomposición de la metrópolis. Inercias y disrupciones de la nueva ecometápolis. DOI: http://dx.doi.org/10.5821/ace.16.46.10658 
La inactividad física contribuye de manera sustancial a la carga global de enfermedad, muerte y discapacidad, y, en España, más del 35\% de la población entre 15 y 70 años no alcanza el nivel de actividad física recomendado por la OMS, y más de la mitad de la población adulta (el 62\% de los hombres y el $47 \%$ de las mujeres) y el $28 \%$ de la población infantil padece obesidad o sobrepeso (Ministerio de Sanidad Servicios Sociales e Igualdad e Instituto Nacional de Estadística, 2017). Ambas estadísticas están asociadas, en mayor o menor medida, a la mayoría de los principales trastornos crónicos prevalentes en adultos —hipertensión arterial, dolor de espalda crónico (lumbar y cervical), colesterol alto, artrosis, varices en las piernas, diabetes, ansiedad crónica y depresión-.

Las últimas recomendaciones de la OMS (2020), por primera vez, además de recomendar un mínimo de actividad física, también proponen recomendaciones para evitar o minimizar los modos de vida sedentarios para distintos grupos de población, lo que supone un importante cambio de paradigma en el que la movilidad activa puede jugar un papel fundamental, que los responsables del planeamiento y la gestión del transporte y del desarrollo urbano municipal y supramunicipal deben abordar. La movilidad activa está asociada a una buena salud percibida que, en el caso concreto de los ciclistas, se completa con una buena salud mental, vitalidad y menor sentimiento de soledad, en el de los peatones, con una mayor vitalidad y mayor frecuencia de contacto amigos o familiares (AvilaPalencia et al., 2018). Constituye la medida más eficiente para mejorar la salud de la población (Rabl y de Nazelle, 2012).

El cambio hacia los modos activos contribuye a proteger el medio ambiente, no solo al posibilitar desplazamientos con emisión casi nula de contaminantes atmosféricos - al caminar o ir en bici, las personas emitimos $\mathrm{CO}_{2}$ - También, y de forma no menos importante, al reducir el consumo energético y material relacionado, por un lado, con la producción, transporte, distribución, venta y mantenimiento de los propios vehículos y de las instalaciones asociadas, y, por otro, con la construcción de las infraestructuras de transporte, aparcamiento y repostaje. La moto, aunque menos nociva que el coche, no es la solución (Roca Cladera, 2017). La electrificación tampoco.

Los vehículos eléctricos, aunque pretendidamente más sostenibles, en realidad lo único que ofrecen es una reducción de la contaminación in situ, manteniendo niveles similares de consumo energético y material que los vehículos con motor de combustión o, incluso, mayores, pues la información relativa a la producción y obsolescencia de los modos eléctricos es tan poco accesible como fiable. Tras un siglo XX protagonizado por la movilidad, el nuevo siglo parece anteponer la accesibilidad y dar preferencia a los modos más asequibles, sostenibles y saludables: los modos activos. Después, el transporte público colectivo y, por último, el vehículo privado motorizado.

La accesibilidad es el objetivo a alcanzar. El medio ha de ser el más sostenible. La iniciativa Sustainable Mobility for All (2019) en su hoja de ruta de acción global hacia la movilidad sostenible, también pone el énfasis en la accesibilidad. Esta fundamenta la propuesta de la Ciudad de cuarto de hora, difundida con enorme éxito durante el último año a escala global, aunque promovida inicialmente para París, según las ideas de Carlos Moreno (2020). Ideas no tan distintas a las propuestas por Colin Buchanan (1963) en Traffic in Towns pero que, sin embargo, es necesario retomar de forma renovada y decidida.

La accesibilidad territorial de este siglo, debido a la mayoritaria localización de las personas, prestará más atención a los ámbitos urbanos, pero no ha de dejar atrás a las zonas rurales o a los municipios de menor tamaño o menos integrados en las grandes áreas metropolitanas. Los modos activos son también la alternativa óptima en estos ámbitos, al tiempo que pueden jugar un papel importante en la recuperación y reactivación de antiguas redes — de carreteras, de ferrocarril, o de trashumanciacon un gran valor añadido de carácter patrimonial, cultural y social.

ACE, 16 (4.6) CC BY-ND 3.0 ES | UPC Barcelona, España | Hacia un urbanismo renovado para la recomposición de la metrópolis. Inercias y disrupciones de la nueva ecometápolis. DOI: http://dx.doi.org/10.5821/ace.16.46.10658 


\subsection{Un nuevo planeamiento dinámico e informado}

Entre los compromisos acordados en la Nueva Agenda Urbana (Naciones Unidas, 2017, p. 9) figura "la reactivación de la planificación y el diseño urbanos y territoriales integrados y a largo plazo", sin embargo, Ascher (2004) ya a principios de siglo señalaba "el fin del futuro previsible y planificable" como una de las características de la tercera modernidad en la que nos vemos inmersos ya desde hace medio siglo y que ha generalizado la metápolis a escala planetaria.

Las tecnologías de la información y la comunicación (TIC) han jugado -y siguen jugando- un papel fundamental en la transformación de la sociedad, la economía y, también, la organización -frente a la planificación - de los asentamientos humanos y la ocupación - frente a la ordenación- del territorio. Los principales actores del capitalismo hacen uso intensivo y extensivo de las TIC, reevaluando constantemente las condiciones de los mercados, tomando decisiones con datos actualizados y revisando las políticas y estrategias en función de los cambios estructurales y coyunturales. ¿Y el planeamiento urbano y territorial?

En el caso de España, el Ministerio de Fomento (2019) —actual Ministerio de Transporte, Movilidad y Agenda Urbana - realizaba recientemente un diagnóstico bastante severo. En relación con la normativa, señala que constituye un "complejo marco normativo [...] que se sigue rigiendo en gran medida por instituciones y estructuras del siglo pasado” (pág. 37).

El análisis de la situación del planeamiento no es más tranquilizadora, cuando se señala que : a) "la actual naturaleza, contenidos y procedimientos de elaboración y aprobación [del planeamiento] no se compadece con una realidad cambiante" a la que no puede dar respuesta "por su propia configuración y características" (pág. 37); b) un desigual presencia territorial y mayoritaria ausencia del necesario planeamiento supramunicipal que acometa la gestión de una realidad que ha desbordado en general los límites municipales, apuntando que "debe quedar bien clara la imposibilidad de solucionar los problemas relacionados con la sostenibilidad global al nivel meramente urbano y municipal, así como las incoherencias que plantea la pretensión de desarrollar el planeamiento solamente a esta escala" (pág. 38); y que, en definitiva, c) "el actual modelo urbanístico español [...] no funciona" (pág. 38).

Coincidiendo en líneas generales con el diagnóstico, la propuesta que se apunta en la misma frase a través de "nuevas fórmulas que compensen la prevención con la inspección y el control posteriores [énfasis agregado]” (pág. 38) genera cierta inquietud.

Sobre la gobernanza, se señala que la "amplia autonomía” de todos los niveles de la Administración "genera algunas disfunciones, como la insuficiente relación entre las decisiones [...], las posibles duplicidades e ineficiencias, la inexistencia de procesos de planificación compartidos o integrados [...] o el [insuficiente o inexistente] desarrollo de sistemas de información compartidos para la gestión" (p. 38). Las consecuencias de estos defectos funcionales de las administraciones son graves y evidentes para el territorio y las ciudades. ¿Qué toca entonces en el siglo XXI?

Lejos de pensar que los nuevos procedimientos deban basarse en la supervisión a posteriori, coincidimos de nuevo con Ascher (2004) y apostamos por progresar hacia una "gestión estratégica urbana" (p. 72) que sustituya a las actuales herramientas normativas y de planeamiento. Inmersos en la Era de la Información, ¿no deberían las TIC y los datos informar y contribuir a definir la estrategia de la ecometápolis?

El nuevo planeamiento lo concebimos como una herramienta dinámica e informada que no aspira a anticipar ni controlar el futuro - está probado que esto no es posible- pero que no renuncia a dirigir el desarrollo y el devenir de la ecometápolis. El nuevo planeamiento no debería fijar el resultado y el

ACE, 16 (4.6) CC BY-ND 3.0 ES | UPC Barcelona, España | Hacia un urbanismo renovado para la recomposición de la metrópolis. Inercias y disrupciones de la nueva ecometápolis. DOI: http://dx.doi.org/10.5821/ace.16.46.10658 
modo de conseguirlo, sino establecer los procedimientos o las reglas de juego con las que las partes involucradas puedan pactar los objetivos y negociar los modos de conseguirlos, asegurando la participación de todos los interesados y la transparencia de los procesos.

Esto requiere de unas administraciones dotadas de profesionales y medios —con capacidades superiores a los actuales - mantener actualizados una serie de indicadores basados en datos que minimicen los tiempos de diagnóstico y análisis necesarios para una toma de decisiones informada que maximicen las probabilidades de éxito, de acuerdo con los imprescindibles requerimientos de sostenibilidad medioambiental, social y económica. El diagnóstico puntual ha de ser casi inmediato, pues contamos con los datos en todo momento.

Este cambio en el concepto, la dinámica y las herramientas de planeamiento no implica en ningún caso su sustitución por un conjunto de proyectos urbanos al uso. Estos serían un proceso más incluido en esta propuesta, sometido a las mismas reglas de juego que estamos planteando de procesos abiertos, participados y transparentes.

Aumenta el grado de incertidumbre - el número de incógnitas del sistema de ecuaciones - pero también la capacidad de afrontar la gestión urbana y territorial — la capacidad de cálculo - que en ningún caso será el resultado de un proyecto en el que necesariamente deberán participar todas las partes involucradas y competentes. La actual mecánica de informes sectoriales ha de dar paso a una nueva dinámica de propuestas negociadas que desde su inicio cuentan con la participación propositiva - no meramente sancionadora- de todos los actores.

Esta incertidumbre podría llevar asociada una dilatación de los procesos o, todo lo contrario. Lo único cierto es que no lo sabemos y que los tiempos de la gestión estratégica urbana serán los que marquen los actores involucrados. Dependerán de las necesidades, los medios y las capacidades de alcanzar consensos.

El proceso no está libre de errores, pero la recopilación de datos permanente facilita la evaluación de cada actuación y posibilita aprender de la experiencia y evitar su repetición, afinar los procedimientos y mejorar la capacidad de respuestas, minimizando la probabilidad de repetir los mismos errores cometidos y la escala de estos. Al contrario que el sistema actual, el nuevo planeamiento no invalida propuestas a priori ni a posteriori, sino que constituye un proceso para destilar la solución óptima.

\subsection{De la rehabilitación y renovación a la praxis de la regeneración urbana integral}

La Declaración de Toledo, firmada el 22 de junio de 2010 por los ministros de desarrollo urbano europeos, hace referencia clara a la regeneración urbana integral como palanca del desarrollo inteligente, sostenible, y socialmente inclusivo en Europa. Se trata de un paso adelante muy notable para la transformación de nuestras ciudades. El paso de la restauración, la rehabilitación, o la renovación urbana a la regeneración urbana integral supone una posición relevante para cumplir con los criterios del desarrollo sostenible. La regeneración urbana integral se basa en actuaciones conjuntas públicas y privadas que tengan como objeto la recuperación habitable del stock de viviendas existente, pero también la mejora de la cohesión social y la revitalización de los espacios, pero también de la habitabilidad en su alcance más amplio. Esta contempla aspectos urbanísticos, arquitectónicos, ambientales, energéticos, financieros, fiscales, y parte de una gran implicación con la especificidad de cada tipo de territorialidad específica.

La incorporación de acciones a nivel social, ambiental y económico inicia un cambio de rumbo de las políticas, directrices, bases y acciones precedentes. Una de las aplicaciones más relevantes de esta

ACE, 16 (4.6) CC BY-ND 3.0 ES | UPC Barcelona, España | Hacia un urbanismo renovado para la recomposición de la metrópolis. Inercias y disrupciones de la nueva ecometápolis. DOI: http://dx.doi.org/10.5821/ace.16.46.10658 
nueva orientación es la que promueve la Ley 2/2004 de mejora de barrios y áreas que requieren una atención especial, del Gobierno de la Generalitat de Cataluña - un programa explicado por uno de sus impulsores clave en Nel·lo (2009). Un programa muy completo e intersectorial que promovió el avanzar en el empoderamiento y la cohesión social, la lucha contra la segregación urbana, el reforzamiento de la identidad social y cultural y la inversión pública supramunicipal para sumarla sinérgicamente a la de las administraciones locales. La nueva política inauguró una forma renovada de actuar con visión y objetivos de transformación integral, sobre barrios vulnerables o barrios sensibles, donde es necesaria la iniciativa pública para generar un cambio de rumbo socio ambiental de los mismos. El programa supuso un referente, todavía vigente, para superar las intervenciones sectoriales e ir más allá de una intervención física, actuando integralmente, incluyendo acciones de tipo socioeconómicas, ambientales y de desarrollo local.

Para profundizar sobre la evolución de experiencias de regeneración conviene seguir, entre otros, los trabajos de Castrillo, Matesanz, Sánchez Fuentes y Sevilla (2014) que proponen una interesante reflexión en torno al concepto de la regeneración urbana y los de Hernández Aja y Rodríguez Suárez (2017) que presentan una visión de los cambios acaecidos en los últimos años en el panorama español y proponen bases y herramientas multicriterio y tipologías de intervenciones.

La regeneración urbana integral, o adoptando una visión escalar más amplia, la regeneración territorial integral debería: dotar de las soluciones de urbanidad básica (todavía); poner límite al sprawl urbano y las discontinuidades urbanas; incrementar las Infraestructuras en red integradas, intermodales, e internodales; promover la regeneración de tramas urbanas habitadas (tramas de habitabilidad y sociabilidad); intensificar la regeneración de tramas urbanas de producción (tramas de actividad y cooperación); favorecer el Personal Rapid Transit para todos y Movilidad como servicio (Mobility as a service); aumentar la movilidad dulce frente y reducir el número de automóviles, permitiendo un progresivo rescate del espacio urbano para las personas; y avanzar hacia la autosuficiencia energética y eficiencia metabólica.

La rehabilitación, la renovación, la regeneración urbana de las tramas urbanas y los barrios que los constituyen, pasa contemporáneamente por actuar en la mejora de lo que identificamos como HAM - habitabilidad, actividad, movilidad-. Tres atributos que determinan las características relevantes de los distintos barrios de la ciudad. Las condiciones de habitabilidad (desde cada estancia hasta la propia ciudad); la diversificación y desarrollo de actividades económicas; y la oferta de movilidad para satisfacer las necesidades cotidianas y de acceso a los flujos de conocimiento, información e intercambios.

El reto fundamental, como cambio de paradigma, para una regeneración integral de las tramas urbanas y los barrios será, por consiguiente, actuar en el plano material-espacial y en la dimensión cívico-social, siguiendo con las nuevas políticas urbanas de mejora de la calidad de vida, la cohesión social, las condiciones ambientales y la biodiversidad. Por ello, la mejora de las tramas urbanas debe centrarse en la triple dimensionalidad espacial del artefacto urbano: el subsuelo, el suelo y el vuelo de la ciudad; siendo clave la interacción entre estos ámbitos. La trama urbana debe ser entendida como una trama-hábitat y por eso hay que lograr el mejor funcionamiento ecosistémico, a nivel morfológico-estructural, metabólico-funcional, y paisajístico-ambiental. Una regeneración integral que supone un alto nivel de reciclaje urbano.

En cuanto a las actuaciones de reciclaje urbano según proponen Jornet y Llop (2014) se pueden establecer cinco grandes grupos de áreas:

"1. Áreas de atención especial (AAE). Se corresponden con los barrios débiles, los centros históricos, los polígonos de vivienda masiva, las áreas suburbanas, los barrios que la Ley de barrios

ACE, 16 (4.6) CC BY-ND 3.0 ES | UPC Barcelona, España | Hacia un urbanismo renovado para la recomposición de la metrópolis. Inercias y disrupciones de la nueva ecometápolis. DOI: http://dx.doi.org/10.5821/ace.16.46.10658 
en Cataluña identificaba. Son barrios en los que se concentran conflictos urbanísticos y sociales y donde es del todo necesaria la actuación intensa y transversal del urbanismo.

2. Áreas de renovación urbana (ARU). Son las áreas ya clásicas de lo que se puede entender como una remodelación interior de la ciudad, donde lo que hay que sustancialmente es reordenar el vacío urbano en la ciudad y donde los gastos de urbanización se limitan básicamente a la obra urbanizadora, ya que habitualmente no hay indemnizaciones ni traslados significativos que haya que tratar en la nueva ordenación.

3. Áreas de compleción o relleno (ACR). Se corresponden con lo que podríamos llamar los alvéolos urbanos, que hay que llenar con elementos o aprovechamientos de la misma naturaleza a los que ya existen -viviendas, actividades, etc.- y en los que a menudo todavía quedan obras de urbanización pendiente y / o cesiones de sistemas de suelos públicos. Son espacios de la ciudad a medio consolidar y medio consolidados, con algunas piezas de suelo pendientes de edificar, que se entremezclan entre las otras edificaciones ya ejecutadas. En general, se corresponden con lo que podríamos llamar actuaciones de dotación.

4. Áreas de transformación de usos (ATU). Son áreas donde de lo que se trata es de cambiar sustancialmente la realidad y destino de los usos actuales para unos usos nuevos. Este es el apartado más complejo y más amplio del reciclaje urbano, ya que pueden tener cabida diferentes subtipos de actuaciones:

- Áreas de oportunidad de nuevas funciones (AOF). Son antiguos espacios industriales obsoletos, sustancialmente vacíos de actividad para que ésta haya cesado, en los que es adecuado plantear un nuevo marco de ordenación y usos. En este caso, los gastos de urbanización corresponden a la obra urbanizadora y en las edificaciones existentes. - Áreas de transformación secuencial (ATS). Se corresponden con ámbitos llenos de usos y actividades, en los que por localización y posición urbana y territorial es posible prever en el futuro una transformación de lo que hay hoy en día, pero que no se puede realizar debido a los elevados gastos de indemnización de actividades. Son sectores que podríamos llamar de "hoy no, pero mañana seguro que sí ", donde habría que establecer un marco de referencia que incorporara esta potencial transformación secuencial del tejido urbano consolidado. Se trata de áreas que podríamos considerar de reprogramación y que en parte se pueden asimilar a las áreas de dotación ya descritas anteriormente.

5. Áreas de centralidad significativa (ACS). Finalmente, estas áreas se corresponden con actuaciones concentradas de nuevas centralidades, con una mezcla importante de usos y actividades y que se identifican con grandes proyectos singulares del proyecto de ciudad. Son, más o menos, las nuevas áreas de centralidad en un municipio; sectores de carácter marcadamente público, con ordenaciones complejas e intensidad de usos, funciones y arquitecturas en un mismo espacio". (pág. 91-93).

Esta taxonomía de actuaciones supone un elenco de situaciones y lógicas proyectuales que se pueden extender en muchas de nuestras realidades urbanas y territoriales. Son transformaciones sobre la espacialidad, pero son impensables sin una decidida y activa regeneración participativa, en la concertación de análisis y en la toma de decisiones; en la concentración estratégica de las acciones palanca, y en la capitalización de los esfuerzos tanto de gestión como de inversión económica.

Desde nuestro contexto socioambiental de la pandemia en curso, vemos todavía más necesaria una regeneración que alcance todas las dimensiones de la habitabilidad y que tenga como eje central la salud, mejorando los entornos físicos saludables y seguros mediante las infraestructuras ecosistémicas. La regeneración integral ecosistémica, por tanto, nos propone alcances urbanísticos y arquitectónicos, y socio ambientales en los espacios públicos y en el sistema más general de espacios abiertos e infraestructura ecológica.

ACE, 16 (4.6) CC BY-ND 3.0 ES | UPC Barcelona, España | Hacia un urbanismo renovado para la recomposición de la metrópolis. Inercias y disrupciones de la nueva ecometápolis. DOI: http://dx.doi.org/10.5821/ace.16.46.10658 


\subsection{La representación de una lectura territorial renovada. La forma como expresión de las nuevas dinámicas y procesos}

Las ciudades y los territorios evolucionan y al mismo tiempo lo hace la forma de interpretarlas y por tanto de describirlas, y viceversa. La lectura territorial pretende entender qué es una determinada realidad en el espacio y en el tiempo. Los modelos para una misma realidad son múltiples. Tal y como lúcidamente lo planteaba Manuel De Solà-Morales (1996), la metrópolis universal no es una expresión o realidad hegemónica.

Diversas interpretaciones pretenden entender y comunicar múltiples dinámicas y procesos que materializan nuevas formas heterogéneas y expresiones fenomenológicas variadas. Expresiones que, a lo largo de la historia, han acabado configurando modelos de ciudad. Dunn et al. (2014) realizan un sugerente recopilatorio que describe "la relevancia y el poder de las ciudades imaginadas y las visiones a lo largo de la cultura popular, un discurso multidisciplinario, junto con una explicación de los métodos utilizados [...] el papel de los diferentes medios y su influencia en la forma en que las ideas se comunican y también se traducen, incluyendo, pero no limitado: diagramas, dibujos, películas, novelas gráficas, literatura, pinturas y fotomontajes; cuestiona el "fundamento" de las visualizaciones de ciudades futuras y si se relacionan con un contexto específico o con un conjunto de condiciones más general [...] el papel de la especulación tecnológica en los escenarios de las ciudades futuras incluyendo: infraestructura, movilidad, sostenibilidad, forma construida, densidad y escala [...] las variaciones en las relaciones socioespaciales que ocurren en diferentes visualizaciones de ciudades, identificando la experiencia vivida y el hábito de los entornos proyectados; [...] se consideran la relación de datos, computación ubicua y digital, tecnologías en visualizaciones contemporáneas de ciudades [...] los temas generales que aparecen derivados de visualizaciones de ciudades británicas y su legado" (pág. 5. Traducción de los autores).

En este sentido, el territorio requiere una nueva representación que supera el mapa y el plano, y se manifiesta en la coreografía como propone Llop (2013), como una nueva manera de describir las territorialidades y las expresiones múltiples de las realidades urbanas y territoriales.

Algunas de las que aportan nuevos análisis, descripciones o interpretaciones de los territorios son: a) las nuevas geografías de la territorialidad y la interrelación entre infraestructura horizontal y la interacción rural-urbana, a través de "figuras" como la città difusa italiana, la Zwischenstadt alemana, - la metrópolis horizontal suiza; b) la representación de la circularidad económica (Marin y De Meulder, 2018); c) la interpretación metabólica y la capacidad para poner en valor la potencialidad de resiliencia urbana (Vandenbroeck, 2017); d) las nuevas espacialidades y formas de vida (Latour y Weibel, 2020); e) la representación de los ciclos y procesos (Corner, 1999); y f) la representación desde la multiplicidad de datos (big data) obtenidos por un incesante rastreo (data mining), seleccionados con análisis espaciales (spatial analytics) y su tematización descriptiva mediante tecnologías cooperativas del análisis visualizado (spatial visualizing) que permite asignar imagen a los datos y sus relaciones, presente en la investigación y en la práctica profesional más avanzada en la planificación urbanoterritorial.

Estas referencias abren puertas a nuevas herramientas o metodologías de comunicación y análisis de la complejidad de los territorios contemporáneos. La coreografía de las realidades territoriales múltiples, diversas, simultáneas nos remite a la configuración de nuevos dispositivos para su regeneración y la formulación de un nuevo concepto que integre las bases y atributos para una transformación en clave ecológica de nuestro mundo urbanizado.

ACE, 16 (4.6) CC BY-ND 3.0 ES | UPC Barcelona, España | Hacia un urbanismo renovado para la recomposición de la metrópolis. Inercias y disrupciones de la nueva ecometápolis. DOI: http://dx.doi.org/10.5821/ace.16.46.10658 


\section{Del Antropoceno depredador a la regeneración metabólica de nuestro mundo urbanizado: la ecometápolis}

Nos encontramos frente a un cambio de era. De transformaciones, transiciones y simultaneidades. Las profundas mutaciones sociales, económicas, políticas y culturales nos enfrentan a un pensamiento proyectual y planificador. Las formas y las funciones de las realidades metropolitanas requieren una nueva epistemología de los análisis, basada en prácticas eficientes y efectivas que muestren que recuperamos controles de los desbordes planetarios que planteó de modo tan incisivo el Stockholm Resilience Center (2019).

Un cambio de era que exige y hace necesario un cambio de paradigma: del crecimiento al desarrollo sostenido y de la competitividad económica a la cooperación. Es en las metrópolis donde se puede verificar una renovada lógica de economía del conocimiento al servicio de la acción, que sea capaz de asegurar desarrollos durables tanto a nivel cuantitativo como en calidades de la habitabilidad para permitir convivir en un mundo todavía en explosión demográfica, necesitado de inclusión y cohesión social. La ciudad, que históricamente ha representado el lugar de satisfacción de múltiples necesidades está dando paso a una ciudad mosaico territorial de dimensiones bioregionales. La escala de la ciudad ahora es ya la escala de las regiones urbanas conurbadas. En esta nueva conformación territorial tanto el territorio urbanizado como los espacios abiertos son claves para su regeneración. Las agendas políticas ya presentan orientaciones sociopolíticas, alentando la creación de nuevos modelos de gobernanza para abordar con geometrías variables interinstitucionales la complejidad de la gestión; la concertación sobre la generación de recursos y empoderamiento entre actores públicos y privados para seguir siendo potenciadores de las ecolonomías, pero sensibles a la equidad inclusiva. Muy atentas a hacerlo con principios de resiliencia para optimizar la disponibilidad de infraestructuras tecnocráticas sin tener que seguir invirtiendo de forma desaforada con modelos de un capitalismo caduco. Cambios en la escala cultural y los modelos sociales de creatividad e innovación. Políticas inspiradas en las agendas internacionales e informadas de los avances del conocimiento y de la necesidad inevitable del intercambio de soluciones y prácticas.

Pero cada territorio debe seguir sus propias directrices y determinar sus opciones concretas en la gestión clave de los ciclos metabólicos de base para que realmente el planeta funcione como un mosaico de prácticas que superan las inercias del Antropoceno y practican una regeneración transformadora para invertir los críticos procesos socioambientales. Una regeneración metabólica como eje axial de las prácticas de la ordenación territorial, de la planificación urbanística, del proyecto y de la gestión metropolitana. Desde, al menos, las siguientes orientaciones: 1) una aproximación de base "economológica" que, aunando economía y ecología, logre un desarrollo equilibrado en términos de eficiencia y resiliencia sostenible; 2) un aprovechamiento de la Inteligencia digital y la digitalización, y las personas como productoras de datos para fortalecer el conocimiento de las potencialidades del territorio; 3) una atención por regenerar antes que seguir ocupando para preservar los espacios todavía libres, la reserva ecosistémica de nuestros barrios, nuestras ciudades, y nuestro planeta; 4) una consciencia operativa basada en la naturación y renaturalización como dispositivos clave para el incremento de los servicios ecosistémicos, mediante el impulso de las infraestructuras ecosistémicas y los espacios abiertos; 5) un enfoque analítico y propositivo que amplía la escala de comprensión de los fenómenos metropolitanos, una interpretación multidimensional y de limites variables y simultáneos según los temas a abordar, una metrópolis transaccional con su territorio suprarregional; 6) una concertación técnica y política que incremente las capacidades de consensos de los protagonistas de la gestión de las transformaciones territoriales, poniendo la metrópolis en relación con las nuevas grandes regiones rururbanas; 7) la práctica de políticas, programas, planes, proyectos y acciones de compensación y equilibrio entre realidades territoriales diversas para facilitar una habitabilidad, actividad y movilidad sinérgicas entre territorios poblados con densidades diferentes;

ACE, 16 (4.6) CC BY-ND 3.0 ES | UPC Barcelona, España | Hacia un urbanismo renovado para la recomposición de la metrópolis. Inercias y disrupciones de la nueva ecometápolis. DOI: http://dx.doi.org/10.5821/ace.16.46.10658 
8) la comprensión de la nueva configuración de la metrópolis como concentraciones polares interconectadas, en vez de islas metropolitanas desconectadas.

Nos situamos en una nueva era que exige alternativas de modelo, exploraciones propositivas para dar respuesta a las impostergables demandas de la sociedad. La recomposición de la metrópolis nos plantea un laboratorio privilegiado para ensayar soluciones para ir más allá de la metápolis con un trabajo centrado en principios ecológicos. Principios que se concretan en proyectos que se pueden replicar como leyenda de referencias para elaborar agendas concretas en cada territorio. Entre las que se ensayan a nivel internacional, encontramos: estrategias para hacer frente común al cambio climático como 100 solutions for climate actions in cities (Sustainia \& C40 Cities Climate Leadership Group, 2015) y trabajos sucesivos; contribuciones a la concreción de los ODS basadas en la economía circular, como Amsterdam Circular 2020-2025 Strategy (Circle Economy and the City of Amsterdam, (2020) experiencias de gestión de la resiliencia metropolitana, como 100 Resilient Cities del Resilient cities network; proyectos innovadores dentro del enfoque y principios para la formulación de barrios sustentables y eficientes, como los realizados en el marco del programa EcoCité del Lab ÉcoCité, ahora LAB2051 en Francia; la práctica de nuevas formas de proyectos urbanos y territoriales centrados en los paradigmas ecológicos entorno al agua, como el proyecto Blue Dunes en New Jersey (Keenan, J. M., Weisz, C., 2017); las propuestas para nuevas formas de movilidad, como la consulta internacional Les Routes du futur $d u$ Grand Paris que realizó una reflexión ambiciosa sobre el futuro de la red viaria que estructura Grand Paris a medio y largo plazo (Forum métropolitain du Grand Paris, 2019) que den respuesta a un imparable proceso de desplazamientos intra, inter y extra metrópolis; la implementación de la renovación energética en el Puerto Oeste de Malmö. Estas y muchas otras podrían recogerse en una base de experiencias que ayudase a revertir modelos obsoletos de planificación y gestión urbano-territorial.

La solución a los grandes retos socioambientales no está sólo en las ciudades o, más bien, lo está en la ciudad mosaico territorial, incorporando todo el territorio como soporte de prácticas innovativas y disruptivas. Avancemos hacia un urbanismo realmente holístico, hiperdisciplinar e integrador. Un urbanismo renovado desde los nuevas directrices estratégicas, bases proyectuales y acciones concretas basadas en principios del metabolismo social para la recomposición de la metrópolis en sus diversos espacios urbanos, rurales y sus interfaces. La vía del urbanismo renovado está en la nueva condición territorial que podemos denominar ecometápolis. Un concepto-dispositivo que nos propone una fusión de componentes analíticos y propositivos a la vez, que nos permitan ir más allá de la polis, considerando la metápolis como realidad que integra la proliferación de entidades urbanas y rurales simultáneas. Una reconceptualización de la metrópolis real que permita superar la condición de ciudad máquina económica disociada del territorio, considerando la necesaria dimensión ecológica global que incorpora la mutualización de la ciudad y su territorio bioregional. La ecometápolis como forma, estructura y relación de la heterogénea realidad urbano-territorial contemporánea en vías de mejora y optimización para abordar una nueva era civilizatoria y una renovada funcionalidad del hecho urbano como hábitat planetario.

\section{Agradecimientos}

Este artículo es fruto de la reflexión producida en el IV Congreso ISUF-H (Barcelona, 28-30.9.2020, https://isuf.arquitectes.cat) que contó con el apoyo financiero del Ministerio de Transporte, Movilidad y Agenda Urbana del Gobierno de España, el Área metropolitana de Barcelona, y el Ayuntamiento de Barcelona; cuyas actas están recogidas en Llop, C., Cervera, M., y Peremiquel, F. (ed.) (2020). Actas IV Congreso ISUF-H Barcelona 2020 "Forma urbis y territorios metropolitanos. Metrópolis en recomposición. Prospectivas proyectuales en el siglo . (https://upcommons.upc.edu/handle/2117/190660)

ACE, 16 (4.6) CC BY-ND 3.0 ES | UPC Barcelona, España | Hacia un urbanismo renovado para la recomposición de la metrópolis. Inercias y disrupciones de la nueva ecometápolis. DOI: http://dx.doi.org/10.5821/ace.16.46.10658 


\section{Autoría}

Ambos autores han conceptualizado, diseñado y escrito de forma conjunta el artículo.

Conflicto de intereses: Los autores declaran que no hay conflicto de intereses.

\section{Bibliografía}

Arnstein, S.R. (2019). A Ladder of Citizen Participation. Journal of the American Planning Association, 85 (1), 24-34. DOI: https://doi.org/10.1080/01944363.2018.1559388

Ascher, F. (1995). Métapolis, ou, L’avenir des villes. Paris, Francia: Éditions Odile Jacob.

Ascher, F. (2004). Los nuevos principios del urbanismo: el fin de las ciudades no está a la orden del día. Alianza (1ª ed. en francés, 2001).

Avila-Palencia, I.; Int Panis, L.; Dons, E.; Gaupp-Berghausen, M.; Raser, E.; Götschi, T.; Gerike, R.; Brand, C.; de Nazelle, A.; Orjuela, J. P.; Anaya-Boig, E.; Stigell, E.; Kahlmeier, S.; lacorossi, F., y Nieuwenhuijsen, M. J. (2018). The effects of transport mode use on self-perceived health, mental health, and social contact measures: A cross-sectional and longitudinal study. Environment International, 120, 199-206. DOI: https://doi.org/10.1016/j.envint.2018.08.002

Barnett, J. (1996). The Fractured Metropolis: Improving The New City, Restoring The Old City, Reshaping The Region. Boulder, CO, Estados Unidos: Westview Press.

Borja, J. y Muxí, Z. (2003). El Espacio público: ciudad y ciudadanía. Barcelona, España: Diputació de Barcelona, Xarxa de Municipis.

Bourdin, Alain (2017). Être métropole dans un monde incertain. Les conférences Plateforme d'Observation des projets et stratégies urbaines, PUCA. France.

Buchanan, C.D. (1963). Traffic in Towns: A Study of the Long Term Problems of Traffic in Urban Areas. Reports of the Steering Group and Working Group Appointed by the Minister of Transport. H. M. Stationery Office.

Capel, H. (1975). La definición de lo urbano. Scripta Vetera, edición electrónica de trabajos publicados sobre geografía y ciencias sociales. Recuperado de http://www.ub.edu/geocrit/sv-33.htm

Castrillo, M.; Matesanz, Á.; Sánchez Fuentes, D. y Sevilla, Á. (2014) ¿Regeneración urbana? Deconstrucción y reconstrucción de un concepto incuestionado. Papeles de relaciones ecosociales y cambio global, 126, 129-139.

Cerdá, I. (1859). Teoría de la construcción de las ciudades aplicada al Proyecto de reforma y ensache de Barcelona.

Cerdá, I. (1867). Teoría general de la urbanización: y aplicación de sus principios y doctrinas a la reforma y ensanche de Barcelona. Barcelona, España: Imprenta Española.

Chalk, W. y Herron, R. (1964). The Walking City.

Choay, F. (1994). Le regne de l'urbain et la mort de la ville. En La ville. Art et architecture en Europe, 1870-1993 (pp. 26-35). Centre Georges Pompidou.

Ciudades y Gobiernos Locales Unidos. (sin fecha) Ciudades metropolitanas y periféricas. La complejidad de la era metropolitana. Recuperado de https://www.uclg.org/es/agenda/ciudades$\underline{\text { metropolitanas-y-perifericas }}$ 
City of Amsterdam. (2020). Amsterdam Circular 2020-2025 Strategy. Circle Economy and the City of Amsterdam.

Climate Watch. (2018). Spain, EU and US Gas Emissions by Sector. Recuperado de https://www.climatewatchdata.org/ghg-emissions

Comisión Europea. (2013a). Building a Green Infrastructure for Europe (p. 24). Publications Office of the European Union. DOI: https://doi.org/10.2779/54125

Comisión Europea. (2013b). Environment: Investing in green infrastructure will bring multiple returns to nature, society and people. Comunicado de Prensa. Recuperado de https://ec.europa.eu/commission/presscorner/detail/en/IP 13404

Corner, J. (1999). Recovering landscapes, essays in contemporary landscape architecture, New York: Princeton Architectural Press.

Dirección General de Urbanismo y Estrategia Territorial de la Comunidad de Madrid. (2006). Suelo ocupado por usos y años en Madrid (1956-2005). Recuperado de https://www.comunidad.madrid/sites/default/files/aud/urbanismo/cma_urb_madrid.pdf

Dora, C. y Phillips, M. (Eds.). (2000). Transport, environment and health (89). World Health Organization. Regional Office for Recuperado de https://www.euro.who.int/_data/assets/pdf_file/0003/87573/E72015.pdf

Dunn, N.; Cureton, P. y Pollastri, S. (2014). A visual history of the future. Future of cities: working paper, Foresight, Government Office for Science.

Dupuy, G. (1991). L’urbanisme des réseux. Armand Colin.

Escudero, L.A. y Gómez, E.J. (2007). El Plan de Descongestión Industrial de Madrid en Castilla-La Mancha: una reflexión geográfica. Estudios Geográficos, 68(263), 497-526. DOI: http://dx.doi.org/10.3989/egeogr.2007.i263.66

Europa Press Data. (2016). Así han evolucionado las distintas causas de deforestación en el mundo. Recuperado de https://www.epdata.es/asi-evolucionado-distintas-causas-deforestacionmundo/489c3356-1512-4b52-ba5e-4627fb3d7931

Forum métropolitain du Grand Paris, (2019). Les routes du futur du Grand Paris. París, Francia: Éditions du Pavillon de l'Arsenal.

Friedmann, J. (1979). Basic needs, agropolitan development, and planning from below. World Development, 7(6), 607-613. DOI: https://doi.org/10.1016/0305-750X(79)90096-2

Garreau, J. (1991). Edge City: Life on the New Frontier. Nueva York, NY, Estados Unidos: Doubleday.

Gehl, J. (2010). Cities for People. Washington, Estados Unidos: Island Press.

Gobierno de España. (2021). Plan de Recuperación, Transformación y Resiliencia Recuperado de https://energia.gob.es/ca-es/Participacion/Paginas/DetalleParticipacionPublica.aspx?k=383

Górgolas, P. (2018). El reto de compactar la periferia residencial contemporánea: densificación eficaz, centralidades selectivas y diversidad funcional. ACE Architecture City and Environment, 13(38), 57-80. DOI: https://doi.org/10.5821/ace.13.38.5211

Hernández Aja, A. y Rodríguez Suárez, I. (2017), De la rehabilitación a la regeneración urbana integrada, Ciudades, 20, 1-20. DOI: https://doi.org/10.24197/ciudades.20.2017.20 
Howard, E. (1898). To-morrow: a peaceful path to real reform. Londres, Reino Unido: Routledge.

Indovina, F. (1990). Città difusa. Istituto universitario di architettura di Venezia. Dipartimento di analisi economica e sociale del territorio.

Izquierdo, J. (2009). La perspectiva agropolitana: la gestión simbionte campo-ciudad en la política regional. Una visión desde España. Instituto para el desarrollo rural de Sudamérica. Recuperado de https://landportal.org/fr/library/resources/ipdrs-biblioteca-50/la-perspectiva-agropolitana-la-gesti\% C3\%B3n-simbionte-campo-\%E2\%80\%93

Jacobs, A.B. (1993). Great streets. Cambridge, Massachusetts, Estados Unidos: MIT Press.

Jacobs, J. (1961). The Death and Life of Great American Cities. N.Y., Estados Unidos: Random House. The Modern Library.

Jaeger, J. A. G.; Soukup, T.; Schwick, C.; Madriñán, L. F. y Kienast, F. (2011). Landscape fragmentation in Europe. European Environment Agency (EEA) y Swiss Federal Office for the Enfironment (FOEN) Recuperado de https://www.eea.europa.eu/publications/landscape-fragmentation-in-europe

Jornet, J. y Llop, C. (2014). Reciclatge urbà, desigualtats socials i problemàtiques urbanes. Quaderns PDU metropolità 04, AMB, Barcelona.

Keenan, J.M. y Weisz, C. (2017) Blue Dunes. Climate change by design. Estados Unidos: Columbia Books on Architecture and the City.

Laínez-Plaza, A.J.; Arranz-López, A.; Badía-Lázaro, R. y Soria-Lara, J. (2018). Entornos de movilidad comercial y dispersión urbana: estudio comparativo de tres áreas urbanas europeas. ACE Architecture City and Environment, 13(38), 101-128. DOI: https://doi.org/10.5821/ace.13.38.5411

Latour, B, y Weibel, P. (eds.) (2020). Critical Zones. The Science and Politics of Landing on Earth. Exhibition Catalog. Cambridge, Massachusetts, Estados Unidos: MIT Press.

Le Corbusier (1943). Urbanisme des CIAM. La Charte d'Athènes. Plon.

Leal, J. y Leyva, M.S. (2011). El espacio público de los inmigrantes. ACE Architecture City and Environment, 17, 317-333. DOI: https://doi.org/10.5821/ace.v6i17.2538

Llop, C. (2011). De les solucions habitacionals a la construcció social de l'hàbitat. Del dret a l'habitatge al dret al plaer d'habitar!. En Gausa, M (dir.): Cap a un Habitat(ge) sostenible., (pp. 113-115). Barcelona: Consell Assessor pel desenvolupament sostenible (CADS), Departament de la Presidència, Generalitat de Catalunya. Recuperado de http://cads.gencat.cat/ca/detalls/detallpublicacio/Cap-a-un-habitatgesostenible-00002

Llop, C. (2013). De la realitat a la representació: de la cartografia a la coreografia. Reptes en la cartografia del paisatge : dinàmiques territorials i valors intangibles. Barcelona, España: Observatori del Paisatge de Catalunya.

Marin, J. y De Meulder, B. (2018). Interpreting Circularity. Circular City Representations Concealing Transition Drivers. Sustainability, 10(5), 1310. DOI: https://doi.org/10.3390/su10051310

Martín, A. (2004) Lo urbano en 20 autores contemporáneos. Barcelona, España: Universitat Politècnica de Catalunya Servicio de Publicaciones.

ACE, 16 (4.6) CC BY-ND 3.0 ES | UPC Barcelona, España | Hacia un urbanismo renovado para la recomposición de 
McHarg, I.L. (1969). Design with Nature. New York, Estados Unidos: Doubleday.

Ministerio para la Transición Ecológica y el Reto Demográfico. (2021). Expresión de interés relativa a flexibilidad del sistema energético, infraestructura eléctrica y redes inteligentes y despliegue del almacenamiento energético, en el marco del Plan de Recuperación, Transformación y Resiliencia. Recuperado de https://energia.gob.es/es-es/Participacion/Paginas/DetalleParticipacionPublica.aspx?k=386

Ministerio de Fomento. (2019). Agenda Urbana Española. Gobierno de España. Recuperado de https://apps.fomento.gob.es/CVP/handlers/pdfhandler.ashx?idpub=BAW061

Ministerio de Sanidad Servicios Sociales e Igualdad, y Instituto Nacional de Estadística. (2017). Encuesta Nacional de Salud España 2017. Informe monográfico de Actividad Física, Descanso y Ocio. Recuperado de http://www.mscbs.gob.es/estadEstudios/estadisticas/encuestaNacional/encuestaNa c2017/ACTIVIDAD FISICA.pdf

Moreno, C. (2020). Droit de cité, de la "ville-monde" à la "ville du quart d'heure." Framncia : Editions de l’observatoire.

Naciones Unidas. (2017). Nueva Agenda Urbana. Naciones Unidas.

Nel·lo, O. (2009). La Llei de barris: quatre anys, deu lliçons. En La Llei de barris, una aposta col·lectiva per la cohesió social Recuperado de https://territori.gencat.cat/web/.content/home/01 departament hormativa i documentacio/documentacio/habitatge millora urbana/barris/la llei de barris una a posta collectiva per la cohesio social/541-af-2-llei de barris-nello tcm32-47591.pdf

Observatorio de Transporte y Logística de España. (2020). Movilidad de viajeros y mercancías. Recuperado de https://observatoriotransporte.mitma.es/movilidad

Organización Mundial de la Salud. (2020). WHO Guidelines on physical activity and sedentary behaviour. World Health Organization. Recuperado de https://www.who.int/publications/i/item/9789240015128

Rabl, A. y de Nazelle, A. (2012). Benefits of shift from car to active transport. Transport Policy, 19(1), 121-131. DOI: https://doi.org/10.1016/j.tranpol.2011.09.008

Rivera Blasco, D. y Ruiz Sánchez, J. (2021). Sprawl logístico en la mega-región urbana de Madrid. El espacio de la distribución entre la dispersión y la centralidad. Ciudad y Territorio Estudios Territoriales, 53(207), 95-118. DOI: https://doi.org/10.37230/CyTET.2021.207.06

Roca Cladera, J. (2017). ¿Es la moto la solución a los problemas de movilidad de la ciudad? ACE Architecture, City, and Environment, 12(35), 11-14. DOI: https://doi.org/10.5821/ace.12.35.5362

Rueda Palenzuela, S. (2012). Libro Verde de la Sostenibilidad Urbana y Local en la Era de la Información, AL21 Red de redes de Desarrollo Local Sostenible, Ministerio de agricultura, alimentación y medio ambiente. Madrid.

Ruiz-Apilánez, B., Ureña, J. M. de, y Solís, E. (2014). La revitalización de la calle: estrategias basadas en la remodelación. Ciudad y Territorio Estudios Territoriales, XLVI(181), 393-411. Recuperado de https://recyt.fecyt.es/index.php/CyTET/article/view/76325

Ruiz, M. y Marmolejo, C. (2008). Hacia una metodología para la detección de subcentros comerciales: un análisis para Barcelona y su área metropolitana. ACE Architecture City and Environment, 3(8), 198218. DOI: https://doi.org/10.5821/ace.v3i8.2464

Sève, B. y Redondo, E. (2020). El pabellón de deseos. Co-creación y co-instalación artística para la mejora del espacio público. ACE Architecture, City and Environment, 14(42), 8200. Recuperado de http://dx.doi.org/10.5821/ace.14.42.8200

ACE, 16 (4.6) CC BY-ND 3.0 ES | UPC Barcelona, España | Hacia un urbanismo renovado para la recomposición de la metrópolis. Inercias y disrupciones de la nueva ecometápolis. DOI: http://dx.doi.org/10.5821/ace.16.46.10658 
Steel, C. (2008). Hungry City, How Food Shapes Our Lives. Londres, Reino Unido: Chatto \& Windus.

Solà Morales, Manuel de, (2004). Contra el modelo de metrópolis universal (Corresponde a la ponencia presentada por el autor en el Congreso Internacional de Arquitectos, UIA Barcelona, 1996). En Martín, Á. (ed.). Lo urbano en 20 autores contemporáneos. (pp. 99-104) Barcelona. Edicions UPC-ETSAB.

Stockholm Resilience Center (2019). The nine planetary boundaries. Stockholm University. Recuperado de https://www.stockholmresilience.org/research/planetary-boundaries/the-nine-planetary-bounda ries.html

Sustainable Mobility for All. (2019). Global Roadmap of Action Toward Sustainable Mobility. Sustainable Mobility for All.

Sustainia y C40 Cities Climate Leadership Group (2015). 100 solutions for climate actions in cities. Recuperado de https://www.realdania.org/publications/in-english/cities100-2015

UCLG. (2017). GOLD IV 2016, Fourth Global Report on Decentralization and Local Democracy Cocreating the Urban Future the Agenda of Metropolises, Cities and Territories. Barcelona: UCLG.

UPC. (2017). Claus per a un nou paradigma energètic. Anàlisi de la situació i tendències. Línies de treball futures de la UPC per a la transició vers un nou model energètic (TME) https://www.upc.edu/ca/sala-de-premsa/pdfs/tme-upc-2017-10-claus-per-a-un-nou-paradigmaenergetic.pdf

Vandenbroeck, P. (2017). Een Metabolische Manier van naar de Wereld Te Kijken; Bruselas, Belgica: Labo Ruimte.

Velázquez Valoria, I., Verdaguer Viana-Cárdenas, C. (2011). Regeneración urbana integral. Tres experiencias europeas innovadoras: Île de Nantes, Coin Street y Barrio de la Mina. Madrid, España: SEPES Entidad Estatal de Suelo.

World Resources Institute. (2016). World Greenhouse Gas Emissions: 2016. Recuperado de https://www.wri.org/data/world-greenhouse-gas-emissions-2016

Zhao, C. (2020). Nomadland. Century City, CA, Estados Unidos: Searchlight Pictures. 